\title{
NEGRITUD Y SERVIDUMBRE EN ATAR-GULL DE LUCIO V. MANSILLA
}

\author{
Mariana Catalin \\ marianacatalin@gmail.com \\ Javier Gasparri \\ jegasparri@gmail.com \\ Instituto de Estudios Críticos en Humanidades \\ Universidad Nacional de Rosario \\ Consejo Nacional de Investigaciones Científicas y Técnicas
}

Resumen: El 19 de mayo de 1864 la compañía de José García Delgado interpreta en el Teatro Victoria la obra AtarGull o Una venganza africana escrita por Lucio V. Mansilla en 1855. Esta no ha sido casi abordada por la crítica literaria. Cuando se lo ha hecho se ha pensado como un antecedente en el surgimiento del teatro nacional (cf Rodriguez, Seibel) o bien se ha enfatizado la figura del esclavo para pensar la pieza en relación con la obra de Eugene Sue (de la que Mansilla toma el personaje) y para leer una crítica al imperialismo inglés similar a la que han caracterizado los primeros escritos del autor (Gasquet). El presente abordaje pretende analizar con detenimiento la pieza y para ello propone hacer foco en la relación de la negritud con la servidumbre. Sin restarle centralidad al primer aspecto pero sumando los aportes que supone dar cuenta de los diferentes énfasis, nos proponemos analizar la descripción y modos de aparición de la negritud en Atar-Gull de Mansilla en el contexto de otras representaciones de la afroargentinidad en la literatura argentina, particularmente de su relación con el poder rosista.

Palabras clave: Teatro Argentino, Siglo XIX, Lucio V. Mansilla, Negritud, Archivo.
Abstract:. On May 19, 1864, the company of José García Delgado interpretted the work Atar-Gull or An African Revenge written by Lucio V. Mansilla in 1855. The literary criticism has paid little attention on it. When it has been readean it has been thought of as an antecedent in the emergence of the nationnal theater (cf Rodriguez, Seibel) or the figure of the slave has been emphasized to think the piece in relation to the work of Eugene Sue (of which Mansilla takes the character) and to read a critique to the English imperialism (Gasquet). The present approach aims to analyze the piece carefully and for this purpose proposes to focus on the relationship of blackness with servitude. Without subtracting centrality to the first aspect but adding the contributions involved in accountting for the different emphases, we propose to analyze the description and modes of appearance of blackness in Atar-Gull de Mansilla in the context of other representations of Afro-Argentineanity in Argentine literature, particularly of its relationship with the power of Rosas.

Keywords: Argentinian Theatre, 19th century, Lucio V. Mansilla, Blackness, Archival. 


\section{La fábula}

El 19 de mayo de 1864 la compañía de José García Delgado interpreta en el Teatro Victoria la obra Atar-Gull o Una venganza africana escrita por Lucio V. Mansilla. En su ya clásica biografía sobre el autor, Enrique Popolizio destaca un dato fundamental sobre el que luego volverá la escasa crítica que se ha ocupado de la obra: la misma habría sido escrita con anterioridad, en 1855, como resultado de una apuesta con sus amigos Manuel Blancas y Esteban Fontán. La misma se haya entonces en relación no tanto con la obra posterior de teatro que escribirá Mansilla, Una tía, o con la creación del Círulo literario, que según Popolizio tiene origen en la cena de celebración de la primera puesta de la obra, sino, antes bien, con las primeras producciones del autor. Particularmente, y en función de la temática no sólo de la fecha de escritura, con "De Adén a Suez", publicada en El Plata científico y literario justamente en 1855 y el recientemente recuperado Diario de viaje a oriente escrito durante su viaje en 1850-51. Y, también, con la recuperación de estas experiencias en "Recuerdos de Egipto" aparecida en enero de ese año en La revista de Buenos Aires.

$\mathrm{Al}$ ocuparse de la manera en que los escritos de viaje construyen la imagen del Otro y, en espejo, la propia, María Rosa Lojo (Mansilla, 2012b) retoma la capacidad singular de Mansilla para transgredir las dicotomías establecidas mediante la articulación de un discurso cosmopolita, tolerante, excéntrico y transformador. En el caso particular de su mirada sobre Oriente y centrándose en el diario, Lojo destaca la crítica 
que hace al imperialismo inglés y al abuso de poder de aquellos que se posicionan como "amos". En el contexto de esas apreciaciones, se generan, según la crítica, dos heteroimagotipos irreverentes para la época: el del inglés, grotesco, y el del nativo, trágico. Estas construcciones seguirán funcionando en las crónicas posteriores, en las que Mansilla presentará a la racionalidad inglesa anulada por la codicia, a lo que sumará una valoración negativa del abuso que se realiza de los débiles.

Muchos de estos tópicos vuelven en el análisis de Atar Gull que realiza Alejandro Gasquet en su prólogo a la reciente reedición de la obra. Al comparar la obra de teatro con la novela de Eugene Sue escrita en 1831 de la que Mansilla retoma no sólo el título sino tópicos y personajes, Gasquet pone el énfasis en el ánimo abolicionista que ambos compartirían. Ánimo que, sin duda, puede pensarse en relación con la crítica al imperialismo inglés que se articula en los otros textos de Mansilla. En este contexto, si bien Gasquet destaca el énfasis puesto en el conflicto romántico y el escándalo que la mezcla racial supondría, lo que insiste en su prólogo es la cuestión del esclavismo y la justicia del acto de venganza. ${ }^{1}$ Esto se ve claramente en la manera en que piensa la relativización de

\footnotetext{
${ }^{1}$ Para pensar la ubicación en el contexto del teatro argentino se puede retomar los artículos de Beatriz Seibel (2008) y de Martín Rodríguez (2005). Rodriguez lee esta producción dramática de Mansilla como incluída en el "teatro de intertexto romántico porteño", particularmente en la "fase de despolitización y reforma" que se inicia en 1852, con la caída de Rosas, y que culminaría en 1884 con el estreno del Moreira por la compañía de los Podesta. De ese período, Rodríguez destaca que comparte aspectos con la obra de Francisco Fernández. Y que por la relación de proximidad que se observaría entre gauchesca y exotismo en la obra, las misma podría relacionarse con El cruzado (1842) de José Marmol, Muza (1850) de Claudio Cuenca y Camila O'Gorman (1856) de Heraclito Fajardo.
} 
la dicotomía civilización y barbarie que, según su análisis, se podría leer en la obra: “el 'bárbaro’ esclavo africano se vale de su inteligencia civilizada para pergeñar una venganza justa; sus crímenes son cometidos aquí en pos de un objetivo loable: el fin de la esclavitud para reencontrarse con su destino de hombre libre" (2017, pp. 36-37). En este sentido, la obra permitiría leer un posicionamiento crítico de Mansilla que se extendería hasta la acción civilizadora de los europeos en América: "la experiencia colonial y el régimen esclavista son dos caras de la misma moneda, siendo ambas realidades indisociables. Atar-Gull puede ser interpretada como la historia del fracaso colonial"' (2017, p. 37).

Si bien, como el mismo Gasquet destaca, a diferencia de lo que ocurre con la lucha de Sue contra la esclavitud en las colonias francesas, el abolicionismo no es una causa que deba ser defendida en el momento en que Mansilla escribe su obra, Alejandro Solomianski nos recuerda, en su libro Identidades secretas: la negritud argentina, que la efectiva y total abolición de la esclavitud no tuvo lugar en Argentina hasta 1861. La perspectiva de Solomianki no solo aporta precisión en torno a las fechas, sino que además permite realizar una distinción fundamental: diferenciar negritud de esclavitud a la vez que señalar la existencia de diversas formas de esta última. En este contexto, por un lado, se especifica la relación entre esclavitud y tráfico, problema que marcará las discusiones que sostienen Tomás Willson y Robeto Wills en la pieza y que, sin duda, pueden pensarse en relación con la discusión en torno al abolicionismo: "Es el tŕafico que se automatiza y se vuelve un fin en sí mismo el que deshumaniza por completo la práctica: 
no se trata siquiera del comercio de seres humanos sino de piezas o "cabezas" de ganado" (2003, p. 67). Pero, a la vez, el análisis de Solomianki permite --al dejar entrever en su desarrollo las diferencias entre las formas de esclavitud de los africanos destinados a las plantaciones y aquellos destinados al servicio doméstico y las formas singulares que esta práctica adquirió en la Argentina-- introducir un factor que la crítica de la obra casi no ha hecho jugar en el análisis: la relación del rosismo con los africanos y los afroargentinos. ${ }^{2}$

Desde la biografía de Popolizio hasta el abordaje de Lojo, han destacado el papel central de los esclavos negros o sus descendientes en la infancia de Mansilla. Y lo han hecho avalados por la manera en que él los vuelve fundamentales en diversos escritos, particularmente en sus memorias, en donde aparecen no sólo el negro Tom y la negra María que se encargan de Lucio y Eduarda a la hora de acostarse sino también el negro Perico:

Aquí aprendí yo a andar a caballo sobre los lomos del negro Perico, que todos los nietos queríamos a cual más, hijo de un esclavo.

Perico se ponía en cuatro pies, trotaba, galopaba y hasta corcoveaba y ipataplum! allá iba yo al suelo cuando lo hincaba demasiado las espuelas (1966, p. 29)

El propósito de este trabajo es realizar una análisis detenido de la pieza centrándonos en los modos de aparición de la negritud (no exclusivamente de la práctica esclavista),

2 Utilizaremos los términos "afroargentino", "negro" y "raza" siguiendo los análisis de Solomianski en el segundo capítulo de su libro, que retoma los aportes de Teun Van Dijk, Frantz Fanon, H.L. Gates, JR., Francois Jacob, Charles W. Mills, Stuart Hall, entre otros, así como también sus prevenciones que apuntan a usos antiesencialistas y desmitificado de los términos. 
retomando algunos de los tópicos que surgen al pensarla en relación con el imaginario orientalista, a través del enlace que suponen las reflexiones sobre el imperialismo, pero, a la vez ,planteando relaciones con otras representaciones de la negritud en Argentina, cercanas al momento en que la crítica coincide en afirmar que Masilla escribió la obra y que vuelven central la relación del rosismo con los afroargentinos, particularmente con Amalia de José Mármol publicada en formato libro justamente en 1855. Finalmente, utilizaremos esta perspectiva para volver sobre la aparición de la negritud en Una excursión a los indios ranqueles, particularmente sobre la figura de "el negro del acordeón".

\section{El sirviente y el levantamiento}

En "De Adén a Suez", Mansilla genera una descripción muy sugestiva de las negras que lo rodean en su desembarco en Adén:

La especie de canoa en la que íbamos se deslizaba con bastante lijereza y sin embargo llevábamos de un lado y otro un enjambre de negras, nadando con tanta velocidad que más parecían monstruos marinos de eso que pinta la fábula en sus caprichosas descripciones, que seres de nuestra especie. De cuando en cuando, les arrojabamos algunas monedas de plata o cobre y en el acto todas zambullían con la agilidad de una tonina, para buscarlas en el fondo; poco tardaban en su submarina investigación y luego volvían a aparecer sobre la superficie del agua, apretando fuertemente en los dientes su tesoro y sacudiendo llenas de júbilo sus salvajes cabezas, que 
cubiertas de una larga melena rojiza, como zahumada en oro, parecían verdaderamente ideales. ¡Cuánto las habría admirado Rafael, tan aficionado a esa clase de cabellos! (2012b, p. 55)

El fragmento oscila entre la más llana animalización del otro y la mirada exotista que si bien las presenta como monstruos, seres no propios de nuestra especie, y genera desde ahí una asociación con la fábula, a la vez se ve impelida a reconocer una belleza que podría haber sido admirada por el propio Rafael y que relaciona salvajismo e ideal.

La primera descripción de Atar-Gull retoma algo de ese carácter fabuloso y a la vez lo desplaza. Antes de su mención, la primera parte de la obra ha puesto el énfasis en las plantaciones y en el problema que le acarrea a Tomás Wilson su piedad ante los esclavos más viejos ya "inútiles". Como dijimos, las discusiones de Tomás con Roberto Wills no giran en torno a la legitimidad de la esclavitud, que no es puesta en duda en ningún momento de la pieza en boca de estos personajes, sino en torno a la moralidad de ciertas prácticas. Mientras que Roberto insiste en que es lícito utilizar en su favor ciertas leyes coloniales para quitarle la vida a los esclavos que ya no sirven y ocasionan gastos, Tomás sostiene sus reticencias, a las que luego renunciará en función de su codicia. Los argumentos de Roberto cruzan dos planos. Por una parte, los esperables, los raciales: los negros no son humanos sino "cuadrumanos", animales, bestias. Como bien lo destaca Solomianki, en el "proceso identificador racista se trata de hacer del "otro" algo no humano, negarle su humanidad, construirlo como negación [...] la "blanquedad" se considera lo 
humano y se designa a la "negritud" como lo subhumano" (2003, p. 54). Pero, por otra parte, le realiza una crítica a Tomás que superpone otra escala de valor y lo coloca entre la hipocresía y la inutilidad: "Tus escrúpulos son indigno de un colono" (2017, p. 80). Éste énfasis en el tráfico y en el carácter de esclavo del negro continuará en las conversaciones que Tomás mantendrá con Brulat sobre sus "cargamentos" y la mano de Sofía y, obviamente, en todos los momentos en que reflexione sobre su posición económica y sobre cómo sustentarla (particularmente en el monólogo con el que abre la Escena VII, una escena típica de crítica intracultural que luego será propia de Una excursión...).

Ahora bien, la presentación de Atar-Gull es precedida por la marcación de un corte con esta lógica. Roberto le dice a Tomás: "Déjate de cumplimientos y hablemos de otra cosa" (2017, p. 81). Plantea entonces el nuevo tema: “'Sabes que es bien extraña la historia del negro ese que te vendí el año pasado?" (2017, p. 81). Si bien estaban hablando sobre los esclavos, la historia de Atar-Gull es otra historia (de hecho, luego, cuando aparezca Brulart, Roberto insistirá en la idea de que la conversación ha dado un giro). Esta primera descripción del negro pondrá en juego, entonces, una serie de problemas que complejizará la presentación de la negritud pensada exclusivamente en relación con el trabajo esclavista en las plantaciones. Por una parte, insistirá la idea de la historia y sobre todo, su carácter de extraño. En primer lugar, Tomás ligará esa extrañeza justamente a lo fabuloso: "efectivamente, tiene algo de fabulosa" (2017, p. 82), dirá sobre la historia de Atar-Gull. Con ese énfasis en lo fabuloso parece relacionarse la 
descripción que le hace Roberto a Brulart cuando éste interroga sobre el tema de la conversación:

\section{ROBERTO}

[...] cuando llamó Vd. hablábamos de otra cosa.

BRULAT

Sin embargo, la puerta continuaba cerrada

TOMÁS

¡Casualidad!

ROBERTO

Es, cierto, porque todo el misterio se reducía a unos elogios, que Tomás me hacía de un negro del que parece estar encantado. (2017, p. 83)

Se sabe que "encantar" posee un triple valor. En primer lugar, la Real Academia española registra el sentido ligado a la hechicería: "Someter a poderes mágicos.". En segundo lugar, lo relaciona con una atracción que presenta como genuina: "Atraer o ganar la voluntad de alguien por dones naturales, como la hermosura, la gracia, la simpatía o el talento" o bien "Gustar en gran medida, agradar mucho". Finalmente, introduce la posibilidad del fingimiento y la traición: "Entretener con razones aparentes y engañosas". La presentación de Atar-Gull se sostiene sobre estos tres sentidos. Dejemos el último para después, para centrarnos ahora en los dos primeros. Cuando Roberto casi acusa a Tomás de haber sido encantado introduce un rasgo exotista al que no se había apelado hasta el momento: que el negro podría haber ejercido algún conjuro. Pero Tomás se resiste e intenta relacionar ese encanto con la segunda acepción. Las característica que la voz del amo/patrón destacan introducen el valor de uso (no de cambio, que es siempre obturado ya que Tomás insiste en que jamás lo vendería) pero no en función con el trabajo que debe 
realizar en las plantaciones, sino con el que realiza como parte del servicio doméstico: la inteligencia le permite descifrar los deseos de aquellos a los que sirve; el valor queda asociado al episodio en el que salva a la familia de una muerte segura al controlar un carruaje con los caballos desbocado. Además de inteligente y valiente, Atar-Gull se nos descubre como solícito y servicial. La relación con la familia está signada por el afecto: "No puedes imaginarte, Roberto [...] el cariño que la familia le tiene" (2017, p. 82). En esta descripción que realiza Tomás, lo que prevalece es la singularidad del negro en relación con los otros que integran su raza no con el nosotros. Pero ante la insistencia de Roberto que busca destacar su carácter de esclavo (la presentación de Tomás hace énfasis en la raza) y su constante tendencia a compararlo con animales, en el discurso de Tomás se articula una leve variante: "este negro no es como los demás; pertenece a esas rarísimas excepciones que su casta suele producir" (2017, p. 84). La figura de Atar-Gull se sostiene entonces entre la excepcionalidad y la posibilidad que abre ese "suele".

Cuando Atar-Gull habla por primera vez, el conflicto amoroso se cruza con el de la raza. Si bien se menciona a sí mismo como "vil negro africano", insiste en sus cualidades. Lo interesante es que su propia presentación vuelve indecidible la tensión que abría la última variante introducida por Tomás: "¿Por qué me habéis dado un alma capaz de sentir y una inteligencia capaz de comprender, y condenado mi raza a la barbarie y la esclavitud, me habéis condenado lo que a tanto otros infelices, a esta tan horrible y desesperante situación?" (2017, p. 98) Si la esclavitud es algo impuesto, por el estado del 
capitalismo imperialista en expansión, el sentido de barbarie se sostiene en tensión: ¿es una caracterización del otro blanco que se rechaza o una calificación que se le impone desde adentro al nosotros negro para destacar al yo? La condena que pesa sobre esos otros infelices ¿se debe sólo a la explotación a la que son sometidos o a que ostentan las mismas características que AtarGull destaca para su persona y que Tomás presentaba como una rareza? ${ }^{3}$

En este punto se vuelve necesario ocuparnos de las tres acciones que giran en torno a la venganza que marca el título de la obra de teatro (que es lo que Mansilla le suma al título de la novela de Sue). Es en torno a estos hechos cuando cobra centralidad el tercer sentido de "encantado" ligado al engaño (¿y a la traición?). El mismo ya se había puesto en juego en esa primera presentación en el modo en que Tomás había narrado el episodio del carruaje: "En aquel momento crítico estuvo sublime de valor. Parecía que algún extraño móvil, más poderoso que la adhesión a su amo le infundía tan temerario arrojo" (2017, p. 83). Atar-Gull ha fingido y fingirá manteniendo ocultos no sólo su amor por Sofía sino también sus propósitos para que sus acciones sean efectivas. Esa duplicidad se potencia, en esta primera mención del protagonista, en torno a los sentidos que se le otorgan a la

\footnotetext{
${ }^{3}$ Estos mismos interrogantes pueden formularse a propósito del segundo monólogo de Atar-Gull que, además, repite ciertas articulaciones: se introduce primero el conflicto amoroso, luego se lo relaciona con la raza y en esa relación el personaje sostiene lo siguiente: "Si al menos yo tuviera algún amigo a quién comunicarle mis dolores!... Pero ni siquiera ese refugio le es dado al pobre esclavo" (2017, p. 117). No se puede determinar si la carencia obedece en el monólogo a una singularidad dentro del nosotros negro o la imposición del otro blanco. Por otra parte, vuelve el primer sentido del encantamiento que puede relacionarse con rasgos exotistas en torno a las visiones que padece el personaje.
} 
inteligencia y a la viveza: Roberto la relaciona con una capacidad animal y con el deber del perro, pero Tomás abre la posibilidad del talento, aunque siempre limitado, al igual que la inteligencia, al servicio del amo y singularizado en la persona de Atar-Gull. El desarrollo de la trama, la manera en que se conduce el protagonista y su relación con los otros irán contestando estas dos primeras acepciones y dando nuevas funciones a la capacidad de Atar-Gull de leer la mente de Tomás.

El asesinato de Brulat se justifica, entonces, como una venganza por el asesinato de su madre. Se apela a los elementos propios del drama romántico: el destino que habilita la ocasión para llevar a cabo el acto (y justifica la arbitrariedad del momento elegido), el espectro, el reconocimiento del personaje y el puñal. De esta primera venganza se destaca la manera en que lo individual se proyecta a lo colectivo. AtarGull no solo le recuerda a Brulat su crueldad para con él y con su madre sino que, tal como lo destaca Martín Rodríguez (2005), le arroja el epícteto de "bárbaro", justamente aquel que se había puesto en juego en su primer monólogo para describir la situación de su raza.

El lento asesinato de Tomás se desarrollará en el epílogo. Allí, Atar-Gull ya no es un esclavo sino tan solo un sirviente, ya que ha ganado su libertad por su actuación en el incendio. Un sirviente al que tanto su amo como Teodoro prometen recompensar por su comportamiento. Pero esta fidelidad que ambos insisten en exaltar mostrará su envés en el desenlace: segundos antes de la muerte, impelido tan solo por el modo de final que requiere el género en que la pieza se inscribe (algo 
que le roba al negro una opción aún más radical: salir indemne de la consumación de su venganza), Atar-Gull revela su plan. Nuevamente aparece el motivo de la historia para introducir las razones que han llevado al protagonista a asesinar a Tomas: "escuche a su vez la narración de una curiosísima historia, cuyo secreto no es ya tiempo de callar" (2017, p. 143). En general, las lecturas críticas han puesto el énfasis en la relación entre la valoración de la venganza y la postura frente a la esclavitud y en el desplazamiento que genera Mansilla hacia el drama sentimental. Gasquet destaca, en este sentido, la manera en que el final de la novela de Sue presentaba, a través de un diálogo del protagonista con Dios, la venganza como justa en función de los padecimientos del esclavo en manos de su opresor; el desenlace del drama de Mansilla exhibiría, en cambio, el asesinato de Sofía como un "exceso vengativo injustificado", aunque esto no implicaría que Mansilla fuera "insensible al problema de la esclavitud" (2017, p. 33): "sin la trata de esclavos como industria civilizada Atar-Gull no hubiera puesto en práctica su inteligencia vengadora. Es la injusticia de la civilización blanca la que lo empuja a ejercer una contraviolencia criminal" (2017, p. 37). Nos gustaría detenernos sobre ese exceso que queda apenas mencionado. Más allá de si, a diferencia del de Sofía, los asesinatos de Brulat, Roberto (que parece haber perecido entre las llamas) y Tomás son justificados por la historia que cuenta el mismo Atar-Gull, la manera en que el personaje presenta lo minucioso de su plan y la forma en que ha logrado engañar no tan solo a Tomás sino a todos los que lo rodean, lo convierte en una figura amenazante; amenaza que la posibilidad de considerar justa su 
venganza y la disculpa de Teodoro con la que se cierra la pieza no logran conjurar totalmente (y que se expande más allá y se vuelve mucho más concreta que la posibilidad de la mezcla interracial y que parece sobrepasar los límites de una crítica intracultural):

Siete años ha que tú y cuantos me conocen admiran la fidelidad de mi cariño, y sin embargo, hace siete años que te odio con toda la fuerza y la hiel de mi corazón ¡Insensato! Todo ha sido fingido, sí, fingido, para saciar mejor la sed de venganza que me devoraba. Durante siete años tu me has creido tu genio tutelar. ¡Estúpido! Yo he sido la causa de tu ruina (2017, p. 145).

Pero, sin duda, el episodio más importante de la venganza es el que implica al colectivo debido al papel que el protagonista desempeña en el mismo y a que en él se pone en juego el modo de pensar la relación entre el uno y los otros dentro de la raza. Ya en el comienzo Tomás había mencionado el ascendiente que Atar-Gull ejercía sobre los otros esclavos, relacionándolo con el carácter singular con el que él insistía en presentar al negro. Si bien la acción, en un primer momento, es introducida a través de elementos propios del drama romántico, la fatalidad como motivo y la noche relampagueante que reproduce el ánimo del protagonista, el tono cambia inmediatamente. En este sentido, el modo en que Atar-Gull la presenta es fundamental: "Os he llamado, hermanos, para denunciaros un hecho atroz, cumpliendo así con los preceptos de nuestra asociación" (2017, p. 128). AtarGull tiene la capacidad de suscitar la ira de los otros miembros de la asociación, demostrando el ascendiente que Tomás había marcado. Pero antes que un ejemplar excepcional dentro de 
una raza abyecta a la que parece no pertenecer, ${ }^{4}$ el diálogo lo muestra tan solo como un buen líder rodeado de sus "hermanos" que inmediatamente comprenden la injusticia del hecho y se aprestan para el levantamiento colectivo. Es decir, la manera en que Mansilla construye esta escena, por una parte impugna el discurso puesto en boca del blanco que intentaba marcar la singularidad de Atar-Gull condenando a su raza. Por otra, muestra que ante la atrocidad el otro tiene la capacidad de percibirla y de reaccionar (ya Atar-Gull cuando había escuchado a Tomás hablar del "negro ahorcado y viejo" había hipotetizado sobre las razones de la siguiente manera: "Alguna víctima quizás de la incansable codicia de nuestros opresores" (2017, p. 100)). La manera en que se presenta aquello que hay que vengar es significativa. La muerte por cansancio no es condenable, sino el hecho de que lo hayan hecho ahorcar:

Bien, hermanos, sabed que vuestro mejor amigo no ha muerto de cansancio como os lo han hecho creer esta mañana al repartiros vuestra ración [...] [ha muerto] ahorcado por Tomás Wilson y Roberto Wills, quienes no pudiendo sacar más provecho de él, porque su enfermedad no le permitía trabajar como vosotros, le entregaron a la justicia acusándole de ladrón [...] si esos dos hombres no mueren, la horca es la recompensa que os aguarda por vuestras vigilias y fatigosas labores (2017, p. 130)

Tomás y Roberto han sido malos Amos. Incluso se puede percibir claramente cómo los integrantes de la asociación pueden comprender la proyección que este incidente singular tiene sobre su futuro y actuar en consecuencia.

\footnotetext{
${ }^{4}$ Recordemos unos de los matices de la primera descripción que realiza Tomás: “...a veces se me figura que la tez de ese esclavo es postiza. ¡Parece increíble que perteneciendo a una raza tan abyecta abrigue semejante corazón!” (2017, p. 83).
} 
El levantamiento puede ser, sin duda, leído en favor de una postura antiesclavista. Pero, en ese contexto, es también fundamental destacar que Mansilla construye una figura de un otro negro (en el que enfatiza una relación de servicio que se desprende de la típica forma de explotación en las plantaciones, esperable en función del contexto en el que ubica la acción) que, en el plano colectivo, puede generar asociaciones. Asociaciones en torno a la idea de que, en el caso de que alguno de sus miembros reciba maltratos percibidos como injustos, "los negros" pueden llevar a cabo exitosamente un levantamiento. Un modo de accionar que no obedece a un exceso de ira, sino que se presenta como razonado y generado desde el nosotros y no por la incentivación de un otro. $\mathrm{Y}$ luego, incluso, en el plano individual, un personaje negro que es capaz de planear una venganza personal apelando a su capacidad de duplicidad y engaño, dando vuelta la fidelidad de la que se lo había hecho portador. Así planteada la construcción del otro negro, parece volverse ineludible pensar esta puesta en escena de Mansilla en relación con la manera en que se presentaron la relaciones entre los afroargentinos y el régimen rosista.

En su análisis del rosismo lo primero que destaca Solomianski es la identificación del mismo con la negritud. Esta identificación es pensada entre la "incorporación" y la "utilización" pero siempre destacando la existencia de un pacto en el que ambas partes obtienen beneficios: "no puede negarse que la política racial del rosismo y los caudillos federales en general (recuérdese también la relación Artigas-Lenzina) frente a la "supremacía blanca" no resulta solamente revolucionaria 
sino también totalmente adelantada a su época" (2003, p. 110). Al ocuparse de la poesía afrofederal y en particular de la no utilización pública del "Himno a Da. Manuela Rosas, cantado por las negras en el día de sus fiestas" el crítico va aún más lejos:

¿No podría tratarse de una manifestación de afecto voluntaria, genuina, en modo alguno inducida $O$ manipulada? Al menos es un texto que, al parecer, no fue utilizado públicamente. Este tipo de relaciones genera interrogantes acerca de la comunmente propuesta e indubitablemente afirmada manipulación de la población afroargentina por parte del aparato discursivo rosista dentro del cual estaría la poesía afrofederal (2003, p. 112)

Pero esa no es la única serie que analiza el crítico. Su acercamiento destaca también la consabida existencia de otros textos que han postulado otro tipo de relaciones entre el rosismo y los afroargentinos que, de diversas maneras y cada uno con sus complejidades, tienden a poner el énfasis en la manipulación. En el epílogo del Facundo de Domingo Faustino Sarmiento, la raza queda ligada ya con dos características que volverán en otros textos: la fidelidad y la docilidad. Las mismas, lejos de suponer un valor, adquieren tintes negativos ya que son asociadas a la adicción al amo. Y en función de esa adicción es que se introduce otro tópico que será central: la traición de los sirvientes y esclavos que "ponían en manos de Rosas un celoso espionaje en el seno de cada familia" (1999, p. 274). En los testimonios de Juana Manso de 1846 se insiste en presentar a ese otro como extranjero $y$, en ese contexto, se vincula la negritud nuevamente con la fidelidad para ligarla a la adoración y a la conformidad con la tiranía. En El matadero de 
Esteban Echeverría, la raza negra, se sabe, queda figurada principalmente en sus mujeres. Sin embargo, como lo explicita Solomianski, también hay hombres negros en el momento del "juicio" al joven. Esa participación los hace pasar a formar parte de la plebe que se unifica en torno a una adhesión ciega al restaurador (inclusión que no surgía de por sí de la actividad con que se presentaba a las mujeres afroargentinas, denostadas en función de una estética antes que en relación con su participación en la violencia del espacio). Una adhesión ilimitada que funda una alianza que el relato intenta mostrar como ilegítima al presentarla no como sustentada por principios políticos, patrióticos o civilizados sino por la violencia, volviendo central la figura del sometimiento --y que es necesario leer en relación con la oposición entre ciudadano y esclavo que se articula en "A la juventud argentina y a todos los dignos hijos de la patria" y que orbitará en todos los desarrollos de El dogma socialista.

Ahora bien, en función de su fecha de publicación, de la particular atención que le presta al rosismo y de los episodios posteriores de la biografía de Mansilla, Amalia de José Mármol se convierte en la referencia central en esta línea. Si pensamos el lugar que ocupa la negritud en la misma en diálogo con la obra de Mansilla, lo primero a destacar es el énfasis de la novela en presentar a los negros y a las negras como parte de la servidumbre. Como señala Solomianski "salvo como servicio personal a los patrones, el trabajo productivo carece de representación" (2003, p. 149). Esta exclusión del trabajo productivo es leída por el crítico como un modo de volver natural la posesión de la riqueza en manos de la oligarquía, que 
es presentada como parte de un espacio ontológico superior caracterizado por su refinamiento y sensibilidad, lo que supone necesariamente un ocultamiento de las relaciones de explotación que permiten la acumulación que expone la novela. Pero cabe hacer una precisión: el texto no oculta todas las relaciones de explotación. Por el contrario, en la relación de Rosas con los afroargentinos la misma queda puesta en primer plano como característica de ese trabajo de servidumbre (algo que no ocurre en el caso de Amalia y sus sirvientes). Y adquiere una característica aberrante en el contexto de la novela: es presentada, obviamente, como una explotación consentida: "el presupuesto es que son tan brutas que realmente admiran al tirano" (Solomianski, 2003, p. 176). Hacia el final y a propósito del alboroto que genera el enfrentamiento con Lavalle, Mármol describe de manera extensa esa relación que la trama ha dejado ya entrever:

Desde los primeros días de nuestra revolución, la magnífica ley de libertad de vientres vino en amparo de aquella parte desgraciada de la humanidad, que había sido arrastrada también hacia el virreinato de Buenos Aires por la codicia y la crueldad del hombre europeo.

Fue Buenos Aires la primera que en el continente de Colón cubrió con la mano de la libertad la frente del africano, pues donde estaba el agua del bautismo no quería ver la degradación de la especie humana. Y la libertad, que así la regeneró y rompió de sus brazos la cadena del siervo, no tuvo en la época del terror ni más acérrimo, ni más ingenuo enemigo que esa raza africana (1965, p. 352).

Mármol acepta el abolicionismo (a la vez que, obviamente, relega a los afroargentinos, "por naturaleza", al "último escalón de la gradería social") pero vuelve sobre el problema central de 
la generación del 37 no a partir de la noción general de pueblo sino específicamente en torno a los afroargentinos. Y traza una clara línea problemática entre la colonia, las leyes de 1813 y el rosismo para pensar los alcances de esa libertad. La raza africana, a la que se le niega el componente argentino, se convierte en un enemigo acérrimo pero, a la vez, ingenuo. Esa ingenuidad tensionará la manera en que continúa la descripción de Mármol. En un primer momento, surge la imagen de un colectivo que debido a que se lo lisonjea y se le estimula el sentimiento de vanidad, soporta "por él todo género de privaciones y sacrificios". Ese "lisonjear", ligado a la ingenuidad, queda lejos del reconocimiento simbólico y mucho más cerca del oportunismo político y la demagogia. Pero Mármol reconoce que Rosas agrega hechos, y entonces se vuelve a tensionar el entusiasmo con el fanatismo. Lo que resuelve la cuestión es ligar la negritud con la posesión de instintos perversos, algo que parece no dejar abierta ya ninguna posibilidad de duda. $\mathrm{Y}$ en ese momento, se introduce nuevamente el tópico de la delación (que ya se había presentado como problema en el capítulo dos cuando Daniel Bello le pide a Amalia que despida a sus sirvientes y que volverá sobre la trama a propósito de la protagonista pero también de otros personajes):

Los negros, pero con especialidad las mujeres de ese color, fueron los principales órganos de la delación que tuvo Rosas.

El sentimiento de gratitud apareció seco, sin raíces en su corazón.

Allí, donde se daba el pan a sus hijos, donde ellas mismas habían recibido su salario y las prodigalidades de una 
sociedad cuyas familias pecan por generosidad, por la indulgencia, y por la comunidad, puede decirse, con el doméstico, allí llevaban la calumnia, la desgracia y la muerte. (1965, p. 352)

Mansilla, el mismo año en que Amalia se publica como novela, retoma entonces la posibilidad de la traición encarnándola en un hombre negro, pero no en relación a la fidelidad con otro Amo sino en función de sus propios principios e intereses. Pone en funcionamiento un agrupamiento colectivo que lejos de dejarse influenciar por el cuento que le han contado puede accionar de acuerdo a las razones que se le presentan como válidas. Desliga entonces a la negritud de su asociación con la fidelidad ciega y con la adhesión irracional. Pero lo hace situando la acción en Pernambuco, amparado por un precedente como Sue y apelando a los elementos estereotipados del drama romántico (y al énfasis en el estereotipo del negro sirviente), que si bien le da voz al otro lo hace en la lengua del nosotros.

\section{E1 bufón}

Más allá de la rememoración afectuosa que Mansilla realiza de lxs negrxs en Mis Memorias, lxs mismxs son también fundamentales en tanto desempeñan un papel clave como marco de escritura de Atar-Gull: "En aquella pieza (...), escribí yo, encerrado, (...) en cuarenta y ocho horas, mi drama Atar Gull o una venganza africana, drama que no fue romántico en sus resultados, aunque de ese género fuera" (1966, p. 102-103). "Aquella pieza" se hallaba en la casa del Tata Tristán y Mamá Mariquita, cuya chacra además para Mansilla "era un oasis", y 
en la que el contacto con lxs negrxs empleadxs era permanente, como por ejemplo con tío Valentín, "un negro rengo, antiguo esclavo, todo un caballero por su fidelidad" y en la que no faltaba el sereno que pasaba cantando: "iViva la Federación! ¡Mueran los salvajes unitarios! ¡Vivid, Representación! Las dos (o las tres o las cuatro) han dado y sereno (o lloviendo)"' (1966, p. 100). De hecho, el comentario sobre la escritura del drama apenas supone una breve digresión en el flujo de este relato, de modo que lo primero presenta ciertamente menos relevancia si lo comparamos con el claro empeño en ofrecer una memoria de juventud mayormente vinculada a los afectos. Podría decirse, entonces, que se trata de un ámbito que supone un 'clima' para la escritura de Atar Gull, en el que lxs negrxs estaban ahí. Más allá de que la obra date de 1855, es decir tres años posterior a Caseros, y por ende la realidad de juventud rosista ya estuviera apagada, de todas maneras la elasticidad de la memoria hace que, aunque sea de modo imaginario, esa realidad se presente como próxima en su contacto. Algo de ese vínculo familiar, además, es señalado por David Viñas:

Una lectura posible de Atar-Gull: el esclavo rebelde, por las historias humillantes de su padre y su madre, remite mediatamente a la genealogía exasperada de Lucio V. Mansilla. La subversión de ese negro brasileño del siglo XVIII funciona proyectivamente, como la venganza simbólica por los padecimientos de sus antepasados. (2005, p. 231)

La segunda obra de teatro de Mansilla, escrita en función de la repercusión que había alcanzado Atar-Gull, se desvía hacia la comedia de costumbre dejando de lado la figura del negro. 
Pero la misma vuelve en un texto inmediatamente posterior y canónico de Mansilla, Una excursión a los indios ranqueles. Y el pasaje es justamente del drama a la comedia ya que el negro encarna el personaje del bufón. En Una excursión... aparece un personaje, el negro del acordeón, integrado al mundo de Mariano Rosas, entre los ranqueles, el cual ante todo permite vislumbrar, como señala Solomianski, la presencia de un afroargentino entre los "desertores de "la civilización"” del otro lado de la frontera $(2003$, p. 38). Este negro, a diferencia de las representaciones previas y las posteriores condensadas en Mis memorias, ya no es un sirviente, aunque vuelve a convocar valores asociadas a ésta: el reconocimiento del superior como amo y la fidelidad como atributo. Mansilla nos confronta, entonces, con una nueva flexión en la figuración de la negritud, casi dos décadas después del rosismo.

El negro irrumpe mientras Mansilla duerme (justo la noche de la orgía) e interrumpe su sueño para cantarle un cielito con su acordeón. De por sí, el asunto no puede empezar bien, pero además se añade una cuestión decisiva: el negro desafina, al parecer, de un modo imposible. Este no es un dato menor en la valoración del personaje en el sentido de que será representado no solo como un negro sino como el negro del acordeón: "Estaban identificados por lo visto, no podían separarse; sin negro no había acordeón, sin acordeón no había negro" (1980, p. 227). Por eso, que Mansilla lo deteste tiene que ver, en principio, con ese acordeón que lastimaba sus oídos. ${ }^{5}$ Para que no lo toque, llega incluso a amenazarlo en más

${ }^{5}$ La relación complicada de Mansilla con la música está planteada en la Excursión, justamente a propósito del negro del acordeón, pero también se encuentra comentada 
de una ocasión con que le enviará a Mariano Rosas un organito de resorte para que pueda prescindir de él y su acordeón, con lo cual "ya no serás un hombre necesario aquî" (1980, p. 224). Ser necesario entre los ranqueles significa tener un lugar de "influencia en palacio" a través de sus "festejadas gracias": el negro con su acordeón es presentado como un bufón, un adulador de Mariano Rosas.

Los circunstantes festejaban las bufonadas del negro.

Estaba radiante de júbilo; se sentaba al lado del cacique; le palmeaba, le abrazaba y mirándole con admiración exclamaba: ¡Ah!, jtoro lindo! ¡Este es mi padre! ¡Yo doy por él la vida! ¿ ¿No es verdad, mi amo?

Mariano hacía un movimiento de aprobación con la cabeza y en voz baja me decía: es muy fiel.

El negro tocaba, cantaba, bailaba y a quien mejor le parecía le adjudicaba una patochada. Para él era lo mismo que fuera un cacique que un capitanejo; un indio que un cristiano. Tenía influencia en palacio y podía usar y abusar de sus festejadas gracias. (1980, p. 228)

Con su acordeón, el negro sigue sosteniendo en el "palacio" de Mariano Rosas la función cultural que lxs negrxs ya tenían en la época rosista, cuando no solo suponían una fuerza de trabajo sino que además deleitaban la imaginación de los niños con sus carnavales y candombes festivos, como el mismo Mansilla recuerda en sus Memorias (1966, p. 83). Pero aunque inseparable del acordeón, más acá de este, el negro es presentado como un obsecuente en su relación con el cacique

en Mis memorias: percibe y se da cuenta cuando la ejecución es desafinada, pero no la disfruta cuando está bien tocada.

No 12. Primer Semestre de 2020 
y como un "insolente" (1980, p. 223) que fastidia a Mansilla, como si la única posibilidad de sobrevivencia de un negro en este momento fuese entre los ranqueles, a costa de buscar protección mediante su desenfado, festivo y desafinado, y de llamar la atención al punto de la impertinencia.

Tal vez por eso además Mansilla termina conectándose con un estilo picaresco en el tratamiento de sus bufonadas. En este sentido, no se ahorra ninguna ironía ni ningún calificativo despectivo casi siempre al borde de la injuria para dirigirse a él o relatarlo. Y el casi da cuenta de cierta ambigüedad narrativa, que procesa de manera más o menos picaresca su fastidio o, dicho de otro modo, el fastidio no llega a ser dramático o violento en tanto es provocado por alguien que aunque es percibido como insoportable, finalmente es inofensivo. De lo que se sigue su resolución próxima a lo risueña antes que agresiva: aquí también, como el casi del garrotazo que no llega a darle porque lo detiene Carmen (1980, p. 223).

$\mathrm{Y}$ es en la historia del negro que se vuelve a imbricar, de manera decisiva, el rosismo:

- Mi amo -me dijo-, yo soy federal. Cuando cayó nuestro padre Rosas, que nos dio la libertad a los negros, estaba de baja. Me hicieron veterano otra vez. Estuve en el Azul con el general Rivas. De allí me deserté y me vine para acá. Y no he de salir de aquí hasta que no venga el Restaurador, que ha de ser pronto, porque don Juan Saa nos ha escrito que él lo va a mandar a buscar. Yo he sido de los negros de Ravelo. Y aquí interrumpió la historia de su vida, entonando, o mejor dicho, desentonando, esta canción:

Que viva la patria 
libre de cadenas y viva el gran Rosas

para defenderla. (1980, p. 222)

Pero Rosas, para el negro, no es apenas el "padre" que lo liberó, esto es, no supone solo una historia entendida como emancipadora que afecta la construcción y valoración del pasado, sino que además, y sobre todo, significa el futuro: estaba, dice Mansilla con cierta ironía, "resuelto a esperar allí hasta la consumación de sus días la venida del Mesías, el regreso del Restaurador" (1980, p. 227). Y Mansilla sabe que ese "Mesías" nunca llegará, y no por escepticismo religioso sino sencillamente por evidencia política empírica. Lo cual, si se restringe la promesa de futuro a esa llegada, es como decir que para el negro no hay futuro. Años después, Mansilla mismo reconoce la extinción, como afirmación y recuerdo en Mis memorias:

El negro y el mulato, el moreno y el pardo más cortésmente, son tipos que se extinguen, como el gaucho sin pago fijo.

El negro y el mulato tenían su prestigio.

Éste pasaba por ser muy inteligente, aquél por ser muy fiel. $\mathrm{Y}$ entre las negras y las mulatas se reclutaban generalmente las amas de leche.

Los negros tenían más prestigio que los mulatos.

Sus procesiones jocundas, con trajes multicolores carnavalescos y sus candombes al son de broncos tamboriles, eran fiestas que impresionaban la imaginación de los niños.

$[\ldots]$

También tenía fama, merecida, el negro, de ser valiente.

Cuando se calientan, son terribles, decían. (1966, p. 83-84) 
Si a modo de comparación volvemos por un momento a Atar-Gull, vemos que allí -como fue señalado- la construcción literaria del personaje se realiza sobre una base romántica y difícilmente recuperable como figuración inmediata, de allí que David Viñas hable de la "entonación operística de Atar-Gull" (2005, p. 231). También esas características son señaladas por Enrique Popolizio, al afirmar que

Se trataba, desde luego, de un africano muy diferente de sus congéneres a los cuales superaba ampliamente en sensibilidad estética, fineza y capacidad afectiva: pensaba y hablaba como cualquier europeo culto de su tiempo, y sus deliquios románticos causaron la admiración y el encanto de su público. (1985, p. 121)

Pero no se trata solamente del personaje de ficción, sino también de los actores reales en la puesta en escena de la obra, quienes, poniendo el cuerpo, exhibían esa suerte de desfasaje en la relación con el lenguaje culto de la obra (como en tantos otros textos del siglo XIX argentino). Y es el propio Mansilla quien lo testimonia: "Excelentísimos, los negros de la compañía del popular [José] García Delgado -iqué deferente era!-, excelentísimos, aunque hablando con acento archiespañol" (1966, p. 103).

A partir de esto, podría leerse el modo en que para Mansilla funciona la relación mediada con lxs negrxs. En la escena de escritura de la obra, lxs negrxs federales de la infancia rosista son un recuerdo, esto es, andaban cerca y próximos al momento de la composición de Atar-Gull pero a su vez ya eran "memorias" para cuando la publicación de éstas en 1904, en las que incluso constata su "extinción". En la misma escena, 
aparecen también otros negros, que son los actores de la obra, esto es, negros que hacen de negros y "con acento archiespañol". Por fin, el propio Atar-Gull, como vimos, movilizando una aspiración 'estetizada'. Entonces, esxs negrxs que, aunque se encontraron cercanxs, aparecen recién como "memoria" o ficcionalizados, dan una pista acerca del modo en que la presencia efectiva o real del negro, sin mediación, resulta al menos incómoda, lo cual nos permite volver, en el contraste, al personaje de la Excursión. 6 No se trataría, vale aclarar, de insinuar un Mansilla racista, pues la hipótesis, en este punto, es literaria antes que ideológica, y de hecho conviene no perder de vista que sus amonestaciones permanentes se dan por el acordeón antes que por negro. Sin embargo, y dado que al fin de cuentas admite lo indisociable del negro y el acordeón, la reciprocidad constitutiva, sigue resultando llamativo su fastidio y su perturbación en el tratamiento. De la identidad en tanto negro, a la identificación 'negro del acordeón', y de allí a la función de bufón, el efecto del personaje en Mansilla parece responder a aquello con lo que no puede lidiar o, precisamente, no puede mediar (casi como ocurre con la orgía, punto ciego o de fuga, aunque procesado con un registro opuesto al del negro: si para éste elige el paso de comedia, para aquella es puro dramatismo y repulsión). El sentido de la mediación, en este caso, se desplaza y aproxima al de traducción, ${ }^{7}$ a partir de

${ }^{6}$ Desde ya que podría objetarse que la Excursión misma, en tanto puesta en relato, supone también una mediación. Pero la diferencia que nos proponemos señalar tiene que ver con una co-presencia vivencial, en la que además el impulso de este texto como crónica otorga no solo un efecto verista sino también la ilusión del registro inmediato.

${ }^{7}$ La proximidad, en su analogía, es paradójica: la traducción tiene lugar en la medida en que la mediación falló, o para mostrar su imposibilidad, aunque en sí misma sea una mediación. 
la lectura que Miguel Dalmaroni realiza de los episodios con el mismo personaje como aquellos que "mantienen un lazo fuerte con los propósitos políticos que Mansilla dice defender y al mismo tiempo los desbaratan"; entonces, dado que "nada puede contra el lugar que el mequetrefe [el negro] se ha ganado entre 'los indios argentinos", se da el salto:

Cuando la eficacia del discurso político o argumentativo cuando la eficacia de lo presentable- puede resultar insuficiente o poco enfática porque su autoridad es sospechosa, la pluma más ligera e irresponsable de la literatura argentina premoderna echa mano de recursos que -cómica y paradójicamente- destartalan su máscara estatal: los recursos persuasivos de lo no serio. (Dalmaroni, 2006, pp. 223-224)

Pero la figura del negro no sólo se le presenta como disruptiva a Mansilla porque lo confronta con los enveses del proyecto colectivo de la nación blanca sino también con aquellos que tejen su historia personal. Es el negro el que vuelve sobre el pasado rosista no solo como parte de la historia de la nación en conformación sino también como episodio en la historia individual del escritor. $\mathrm{Y}$ articula una de las preguntas más conflictivas de Una excursión...

-¿Usted es sobrino de Rosas?

-Sí.

-¿Federal?

-No.

-¿Salvaje?

-No.

-¿Y entonces, qué es?

-iQué te importa!

El negro frunció la frente, y con voz y aire irrespetuoso:

-No me trate mal porque soy negro y pobre -me dijo. 
-No seas insolente -le contesté.

-Aquí todos somos iguales -repuso, agregando algo indecente. (1980, p. 223)

Como ha destacado en general la crítica, Mansilla pone en boca de un otro que claramente no puede cuestionarlo la pregunta por su relación con el rosismo, pregunta acuciante en el momento de escritura de Una excursión... Pero leída en relación con Atar Gull esta escena adquiere un nuevo matiz. Cuando aquel al que el negro llama "amo" no retribuye correctamente aquello que se le otorga (la defensa de los logros del rosismo y la canción que los conmemora), la adhesión y el reconocimiento de la autoridad inicial se resquebraja. Entonces, Mansilla figura un otro que, a la manera de los sirvientes del ingenio brasilero, puede rebelarse cuando sus intereses se ven comprometidos. Así, a la vez que se confronta con la incomodidad que produce esa figura sin las mediaciones de las convenciones del drama romántico o la temporalidad pasada, vuelve a desligar la negritud de su asociación con la fidelidad ciega y con la adhesión irracional propia del discurso antirrosista.

Por lo demás, que el negro esté del otro lado de la frontera ya es toda una figuración ligada paradójicamente al borramiento. Mansilla, "irresponsable" de sus funciones de Estado o propósitos políticos, se entrega en la Excursión festivamente "como un aventurero de sí o como un artista" y aquello que el texto "prodiga como si no desafiase a nadie ni a nada" (Dalmaroni, 2006, p. 227) resuelve como traducción picaresca, mostrando a cada paso sus reservas, la aparición del negro-bufón. 


\section{Problemas de archivo}

Si, como sostiene Solomianski, la negación del componente poblacional afroargentino es a la vez efecto y procedimiento del principio constructivo que ha regido la configuración hegemónica del imaginario nacional, el traslado de la acción a Pernambuco que realiza Mansilla en Atar-Gull... puede leerse en esa línea. ${ }^{8}$ A la vez, en función del enfoque que parece requerirle la pieza a Mansilla, se enfatiza "la imagen cristalizada de una afroargentinidad colonial dedicada exclusivamente a las tareas domésticas y a los servicios" (2003, p. 72), ya que el trabajo en las plantaciones y el tráfico es mencionado para luego ser desplazado. La tensión entre las operaciones es por sí misma relevante. Pero, además, es en esas tensiones que la obra de Mansilla genera imágenes alternativas de la negritud.

En la "Noticia" que encabeza la reedición del texto en Orígenes del teatro nacional en el tomo III de 1926, Carmelo Bonet presentaba el siguiente problema "¿Cómo exigir estudio de caracteres, descripción de ambientes, justeza de formas? Tales virtudes huelgan en el melodrama de Mansilla. Por eso estéticamente es obra muerta y se la reedita como documento y nada más" (1926, p. 358). Las discusiones más recientes en torno a los alcances y límites del archivo y a los desarrollos en torno a lo que implica pensar en una "obra completa" nos

\footnotetext{
8 Solomianski también destaca, al analizar las concepciones de Ricardo Rojas, que "el "pensamiento" de la "blanquedad" argentina o bien tiende a ignorar a la "negritud" argentina, o la instala en los tiempos de la esclavitud colonial, o si se refiere a la cuestión de la "raza" puede llegar a corporizarse en una línea de pensamiento inaceptable" (2003, p. 58).
} 
permiten salir de la dicotomía valor documental / valor artístico.

En este sentido, si entendemos el archivo ya no solo asociado fácticamente a un repositorio documental sino en términos productivos, como práctica que hace al sistema de los enunciados-acontecimientos y permite la emergencia de ciertas discursividades específicas (Foucault, 1979), entonces el enfoque adquiere otra perspectiva. Ésta, por su parte, al tomar la inflexión de archivo de escritor, es la que permite en el caso de Mansilla interrogar en torno a la posibilidad de su "obra completa", desprendida a su vez de una visión totalizante, y en cambio inscripta en la tensión entre su fragmentarismo (tan señalado por sus críticos históricos) y sus aspiraciones balzacianas. Tal proyección daría lugar a nuevas consideraciones en el marco del sistema de consagración literaria y cultural, junto a los criterios que lo definen e implican procesos de publicación y circulación específicos, especialmente ligados en este caso al contexto argentino del siglo XIX en el que estos términos resultan problemáticos. El tratamiento de la obra de Mansilla en esta dirección daría paso no solo a conceptualizaciones críticas de más amplio alcance sino además a una relectura integral de su producción en la que la focalización de piezas no canónicas toman sentido en sí mismas (a partir de los problemas literarios, culturales o históricos que enuncian) y además afectan la lectura de zonas ya ampliamente conocidas, como hemos visto con Atar-Gull. 


\section{Referencias Bibliográficas}

Dalmaroni, M. (2006). Una república de las letras. Rojas, Lugones, Payró. Escritores argentinos y Estado. Rosario: Beatriz Viterbo.

Derrida, J. (1997). Mal de archivo. Una impresión freudiana. Madrid: Trotta.

Didi-Huberman, G. (2012) "El archivo arde". Mimeo de traducción interna: UNLP. https://filologiaunlp.files.wordpress.com/2012/05/elarchivo-arde1.pdf

Echeverria, E. (2004). La cautiva. El matadero. Buenos Aires: Losada.

---. (2007). El Dogma Socilista y Otros Escritos. La Plata: Terrmar.

Foucault, M. (1979). Arqueología del saber. México: Siglo XXI Editores.

Guillory, J. (1993). The problem of literary canon formation. Chicago: University of Chicago Press.

Laera, A. (2016). "Sobre algunas variantes de la consagración cultural en la Argentina: la obra completa". Carlos Battilana y Martín Sozzi (Coords.). Genealogías literarias y operaciones críticas en América Latina. Buenos Aires: NJ Editor, 59-66.

Mansilla, L. V. (1926). Atar-Gull. Orígenes del teatro nacional. Sección documentos. Tomo III (6). Buenos Aires: Imprenta de la Universidad.

---. (1966). Mis memorias. Buenos Aires: Eudeba.

---. (1980). Una excursión a los indios ranqueles (2 tomos). Buenos Aires: CEAL.

---. (2012a). El excursionista del planeta. Edición y prólogo de Sandra Contreras. Buenos Aires: FCE. 
---. (2012b) Diario de viaje a Oriente, 1850-51, y otras crónicas del viaje oriental. Edición a cargo de María Rosa Lojo. Buenos Aires: Corregidor.

---. (2017). Atar-Gull o Una venganza africana y Una tía. Dos piezas teatrales. Prólogo de Axel Gasquet. Villa María: Eduvim.

Mármol, J. (1965). Amalia. Novela histórica americana. Buenos Aires: Sopena.

Nash, A.(ed.). (2003). The Culture of Collected Editions. London: Palgrave Macmillan.

Popolizio, E. (1985). Vida de Lucio V. Mansilla. Buenos Aires: Pomaire.

Rodríguez, M. (2005). "Mansilla y el teatro de intertexto romántico." Osvaldo Pelleteri. Teatro, memoria y ficción. Buenos Aires: Galerna.

Sarmiento, D. F. (2000). Facundo o civilización y barbarie en las pampas argentinas. Buenos Aires: Planeta.

Seibel, B. (2008). "Prólogo". Leopoldo Zuloga et al. (Eds.). Antología de obras de teatro argentino desde sus orígenes a la actualidad: 1860-1877: obras de la organización nacional. Buenos Aires: Instituto Nacional de Teatro.

Solomianski, A. (2003). Identidades secretas: la negritud argentina. Rosario: Beatriz Viterbo.

Viñas, D. (2005). Literatura argentina y política. Tomo I: De los jacobinos porteños a la bohemia anarquista. Buenos Aires: Santiago Arcos. 